\title{
Change Detection with GRASS GIS - Comparison of images taken by different sensors
}

\author{
Michael Fuchs, Rainer Hoffmann and Friedhelm Schwonke \\ Federal Institute for Geosciences and Natural Resources (BGR) \\ michael.fuchs@bgr.de
}

Keywords: Remote Sensing, Change Detection, diversity, GRASS, Yemen

\begin{abstract}
Images of American military reconnaissance satellites of the Sixties (CORONA) in combination with modern sensors (SPOT, QuickBird) were used for detection of changes in land use. The pilot area was located about $40 \mathrm{~km}$ northwest of Yemen's capital Sana'a and covered approximately $100 \mathrm{~km}^{2}$. To produce comparable layers from images of distinctly different sources, the moving window technique was applied, using the diversity parameter. The resulting difference layers reveal plausible and interpretable change patterns, particularly in areas where urban sprawl occurs.

The comparison of CORONA images with images taken by modern sensors proved to be an additional tool to visualize and quantify major changes in land use. The results should serve as additional basic data eg. in regional planning.
\end{abstract}

The computation sequence was executed in GRASS GIS.

\section{Introduction}

GRASS GIS (http://grass.osgeo.org) with extended functionality and operability is more than a common geographic information system. It is powerful in raster data processing, offers fundamental functions in terrain- and landscape analysis with extended tools for hydrological modeling and a small functionality for remote sensing. Furthermore it can be used to process three dimensional data. This powerful functionality can be used as a frame for studies, which use GIS in combination with remote sensing tools.

\section{Change Detection - State of the art}

Change Detection is a group of methods commonly used in remote sensing. Because of the repetitive coverage of earth orbiting satellites at short intervals and consistent image 


\section{Change Detection with GRASS GiS - Comparison of images taken by DIFFERENT SENSORS}

quality, methods of Change Detection have become part of environmental observation systems (Lunetta \& Elvidge 1999; Owe 2007).

Change Detection is defined as: "The sensing of environmental changes that uses two or more scenes covering the same geographic area acquired over a period of time." (Glossary of Canada Centre for Remote Sensing, http://www.ccrs.nrcan.gc.ca/glossary) Aside from visual interpretation different algorithms are applied.

Essential aims of Change Detection are:

- Detection and evaluation of land use changes

- Support the monitoring of disasters triggered by geological, meteorological or man made factors.

The use of Change Detection algorithms requires two preconditions:

1. Changes in land cover must result in changes in radiance values.

2. Changes in radiance due to land cover changes must be large with respect to radiance changes caused by other factors, such as atmospheric conditions, sun angle or vegetation phenology.

The preconditions mentioned are based on processing scenes from the same sensor type. The scenes acquisition should be done carefully because differences in radiation, precipitation and surface temperature in combination with phenological variations lead to discrepancies in reflectance properties. These sources of interference have to be extensively eliminated. The phenological variations are reduced by using scenes taken at the same season of the year. Additionally, climate data should be available to assess the phenological stage of the vegetation.

Well-known satellite missions have been operating continuously for decades. Landsat missions for instance have been delivering images since 1972 with repetition rates of 18 days (MSS) and 16 days (Landsat 4, 5, 7), respectively.

The data preparation includes:

- Image registration with geometric correction

- Radiometric calibration with atmospheric correction

The goal is to achieve high quality images with geographic precision of less than one pixel and correlation of radiometric calibration close to 1 .

The applied methods of Change Detection comprise simple difference procedures and multivariate statistical routines. Change Detection can be used directly to multiband stacks or derived resp. classified layers. An overview of Change Detection methods can be found in Théau (2006), the comparison and evaluation of methods and their applicability is described in Peinado (2001). Some major definitions used in remote sensing are given below according to Théau (2006) and Yang (1999):

- Image differencing

- NDVI, Tasseled Cap 


\begin{tabular}{|c|c|c|c|c|}
\hline & MODIS & Landsat & SPOT & QuickBird \\
\hline Continuity & Since 1999 & Since 1972 & Since 1986 & Since 2002 \\
\hline Spatial Coverage & $\begin{array}{l}2330 \mathrm{~km} \text { (cross } \\
\text { track) by } 10 \mathrm{~km} \\
\text { (along track at } \\
\text { nadir) }\end{array}$ & $170 \times 183 \mathrm{~km}$ & $60 \times 60 \mathrm{~km}$ & $16.5 \times 16.5 \mathrm{~km}$ \\
\hline Spatial Resolution & $\begin{array}{lr}250 \mathrm{~m} \text { (bands } \\
1-2 \text { ) } 500 \quad \mathrm{~m} \\
\text { (bands } 3-7 \text { ) } \\
1000 \mathrm{~m} \text { (bands } \\
8-36 \text { ) }\end{array}$ & $\begin{array}{l}30 \mathrm{~m} \text { (pan } 15 \\
\mathrm{~m})\end{array}$ & $\begin{array}{l}10 \mathrm{~m} \text { (pan } 5 \text { or } \\
3 \mathrm{~m})\end{array}$ & $\begin{array}{ll}2.44 \quad \mathrm{~m} & \text { (pan } \\
0.61 \mathrm{~m}) & \end{array}$ \\
\hline Band Numbers & $\begin{array}{l}\text { Multispectral } \\
(36) \quad \text { (hyper } \\
\text { spectral) }\end{array}$ & $\begin{array}{l}\text { Multispectral } \\
(7)+ \\
\text { panchromatic }\end{array}$ & $\begin{array}{l}\text { Multispectral } \\
(4)+\text { panchro- } \\
\text { matic }\end{array}$ & $\begin{array}{l}\text { Multispectral } \\
(4)+\text { panchro- } \\
\text { matic }\end{array}$ \\
\hline Repetition & 2 days & 16 days & $2.5-26$ days & $1-3.5$ days \\
\hline Acquisition Costs & free & $\begin{array}{l}\text { selective im- } \\
\text { agery free, } \\
\text { further cost } \\
0.02 \$ / \mathrm{km}^{2}\end{array}$ & $0.94 \$ / \mathrm{km}^{2}$ & $22 \$ / \mathrm{km}^{2}$ \\
\hline
\end{tabular}

Tab.1: Technical Data of Selected Remote Sensing Satellites

The Tasseled Cap transformation (TC) optimizes data viewing for vegetation studies as one of the available methods for enhancing spectral information content of Landsat TM. Four bands are calculated: brightness, greenness, wetness, and haze.

- Image rationing

- Principal Components Analysis (PCA)

This technique is usually used to reduce the number of spectral components (spectral bands) to fewer principal components accounting for the most variance in the original multispectral images. Image spectral bands of two or more dates are treated as a single data set. After performing PCA, information that is common to multidate images is mapped to the first component (unchanged areas) whereas information that is unique to one of the dates is mapped to the following components (changed areas).

- Composite Analysis

Supervised and unsupervised classifications are used to analyze these datasets. Classes where changes occurred are expected to present statistics significantly different from where changes did not take place.

- Change Vector Analysis

- Comparison of post-classifications

The critical step of all mentioned methods is deciding where to place the threshold for changes. Furthermore the exact nature of the changes needs a careful interpretation including the knowledge of the investigation area including ground checks. 


\section{Reconnaissance Satellite Photos - CORONA}

The term stands for a series of U. S. Military reconnaissance satellites (KH 1 to $\mathrm{KH}$ 5) which were operated between 1959 and 1972. The satellites of the CORONA series delivered panchromatic photographs of many areas of the world.

Images of the first generation were declassified at the end of the Nineties. The ground resolution of the two KH-4 systems $(1963$ - 1972) ranged between 2 and $3 \mathrm{~m}$. The photographs are $30 \$$ each and can be ordered under http://edcsns17.cr.usgs.gov/EarthExplorer.

CORONA photos are used in various research projects. One application is the derivation of elevation models because many scenes provide stereoscopic records (Schmidt et al. 2001). Grosse et al. (2005) used CORONA images for the visual interpretation of thermokarst processes. Another area of application comprises the preparation and support of archeological excavations (Goossens et al. 2002). In geological mapping CORONA images are required where other high resolution images are missing. Lorenz (2004) completed the mapping of Paleozoic stratums in Russian Arctic with CORONA images.

\section{Method}

CORONA images are an essential source of information in particular for those decades where other high resolution images are missing. This applies to the sixties of the last century when only military reconnaissance satellites were operating. However, only Corona images are available for this decade since 1996 (http://edc.usgs.gov/guides/disp1.html).

The methods of Change Detection mentioned above are based on scenes taken by the same sensor type at different dates. The method described in this paper is based on the image differencing method. Scenes are compared that were taken by different sensors. For this, the steps for the preparation and harmonization of the image information are very important. These working steps comprise the geometric correction of the CORONA image, the transformation of the RGB channels of the modern satellite data into one panchromatic channel and the resample process into the pixel resolution of the CORONA image. Then the subsequent moving window algorithm can be applied. The computation sequence ends with the subtraction step (Fig. 1).

The core of the computation sequence uses the moving window technique. This technique is offered by the GRASS raster module r.neighbors (http://grass.osgeo.org). The command r.neighbors can be run with different parameters. Basically two groups of parameters exist. The first group comprises the statistical parameters. The second group comprises parameters commonly used in landscape analysis (McGarigal \& Marks 1995). These two parameters are the diversity and the interspersion. Diversity is defined as the number of different values within the neighborhood. The computation with parameters of the second group leads to results which calculate pixelwise diversity as dimensionless value. Therefore the comparison between images taken with different sensors is possible as outlined now.

For each pixel the number of different neighborhood pixel values has to be identified and stored as a new value. Therefore the size of the moving window is to be considered as sensible value with strong influence on the result layers (Fig 2). The size of the moving window has 


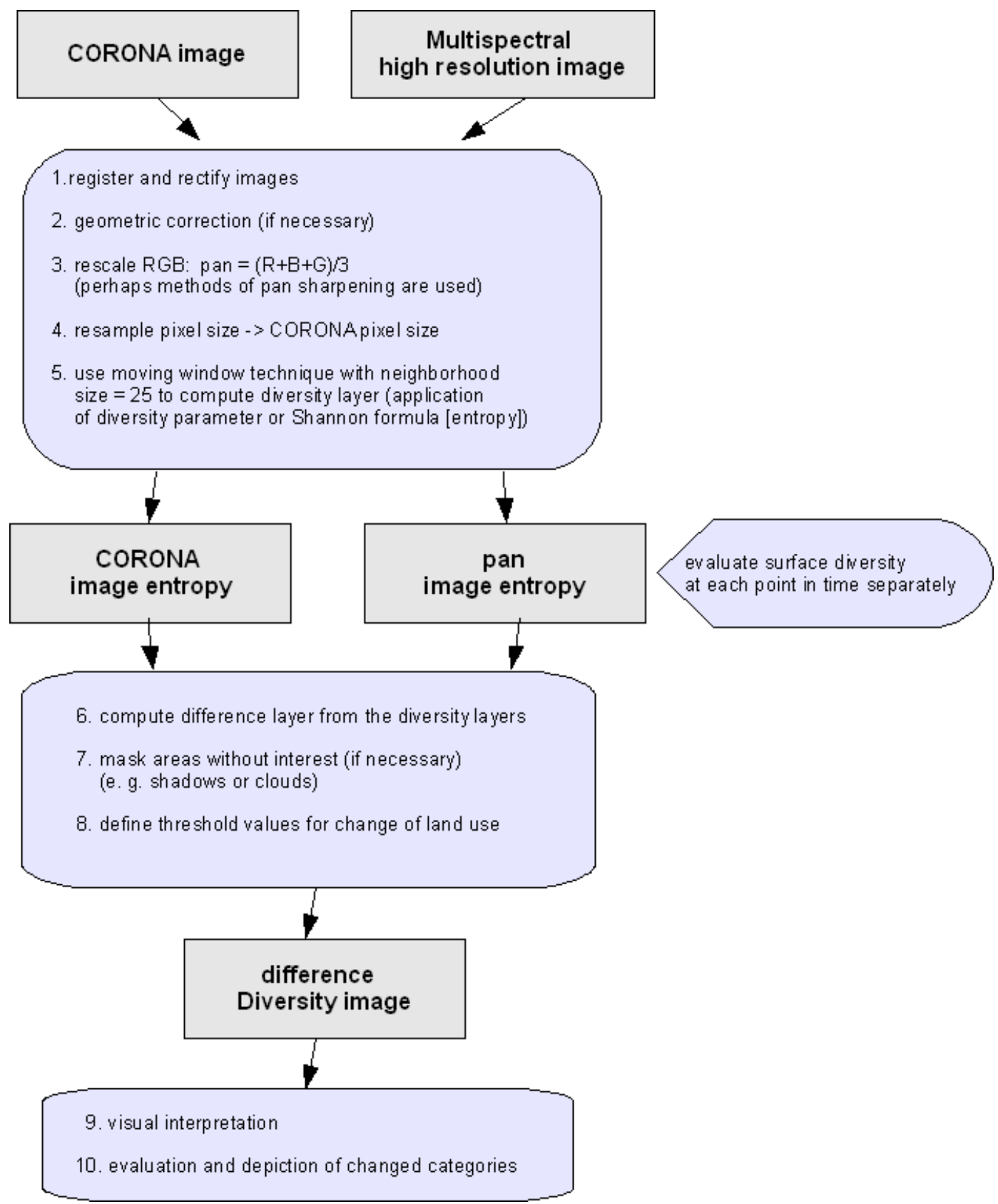

Fig. 1: Flow chart of sequential computation

strong influence on the pattern of diversity. Tests show that the matrix size of $25 \times 25$ delivers interpretable result layers; hence 625 neighboring cells are included in the computation. With the pixel size of $2.5 \mathrm{~m}$, the radius of influence is $12 * 2.5 \mathrm{~m}=30 \mathrm{~m}$ (leaving out the central pixel).

In addition to the diversity parameter the entropy formula (Eq. 1) is used in the computation. The Shannon Diversity Index (SHDI) is computed in our own application written in Fortran 90 and the results are dumped as absolute values. The SHDI is based on the information theory and is also called as Negentropy (Palm 1985). It presents the amount of information 


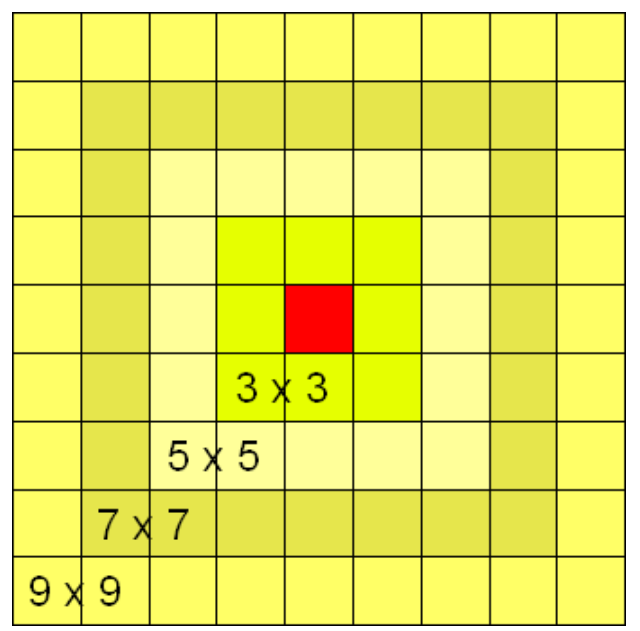

Fig 2: Inclusion of neighborhood size in the moving window

for a defined quantity. The entropy formula is commonly used in different research areas, such as landscape analysis (McGarigal \& Marks 1995). In soil geography it is called areal heterogeneity. Here the entropy is a measure of uncertainty. In this discipline it was discussed as indicator of landscape structure (Altmann \& Haase 1987). The measure of uncertainties for a defined quantity of information is basis of evaluations in human geography (Paulov 1991) and it is discussed in cartography to support the process of generalization (Bjorke 1996).

$S H D I=-\sum_{i=1}^{m}\left(p_{i} * \ln p_{i}\right)$

- with range: 0 - $\ln m$

- $p i$ - Proportion of number of one value to values total

- $m$ - Count of different values

- $S H D I=0$ if window contains the same value in all cells.

- SHDI increases with the number of different values in the window.

- Maximum entropy is reached when all values are different, the same as $\ln m$.

The result layers are intersected by subtraction. Sources of error originating from clouds or shadows can be masked. Therefore results of supervised or unsupervised classifications can be used because such classes normally have a good delineation from other classes in the multivariate space.

\section{Area of investigation and data input layer}

The test site is located north west of Yemen's capital Sana'a and comprises an area of $10 \mathrm{x}$ $10 \mathrm{~km}$. In this arid to semi-arid climate zone, an ancient cultivated land with deficiencies of water occurs. The test site is composed of a cuesta landscape with altitudes between 2500 and $3000 \mathrm{~m}$ a.s.l. with wide-stretched valleys and a network of wadis (Fig. 3). Farming within the test site is characterized by extensive irrigation using groundwater from wells. On a limited scale run-off water is used, too. Arable land mainly is located in the valleys and on 


\section{Change Detection with GRASS GiS - Comparison of images taken by DIFFERENT SENSORS}

man-made terraces located on the pediments in front of the escarpments and on dip slopes. Aside from land use such as arable farming, various other categories of land use can be found (Fig. 4).

Due to the long term technical cooperation between the geological surveys of the Republic of Yemen and Germany, there are satellite images available in the Federal Institute for Geosciences and Natural Resources (BGR). For this study SPOT data (http://www.spot.com) and GoogleEarth-QuickBird data (http://earth.google.com) were chosen for the comparison with CORONA images (Tab. 2).

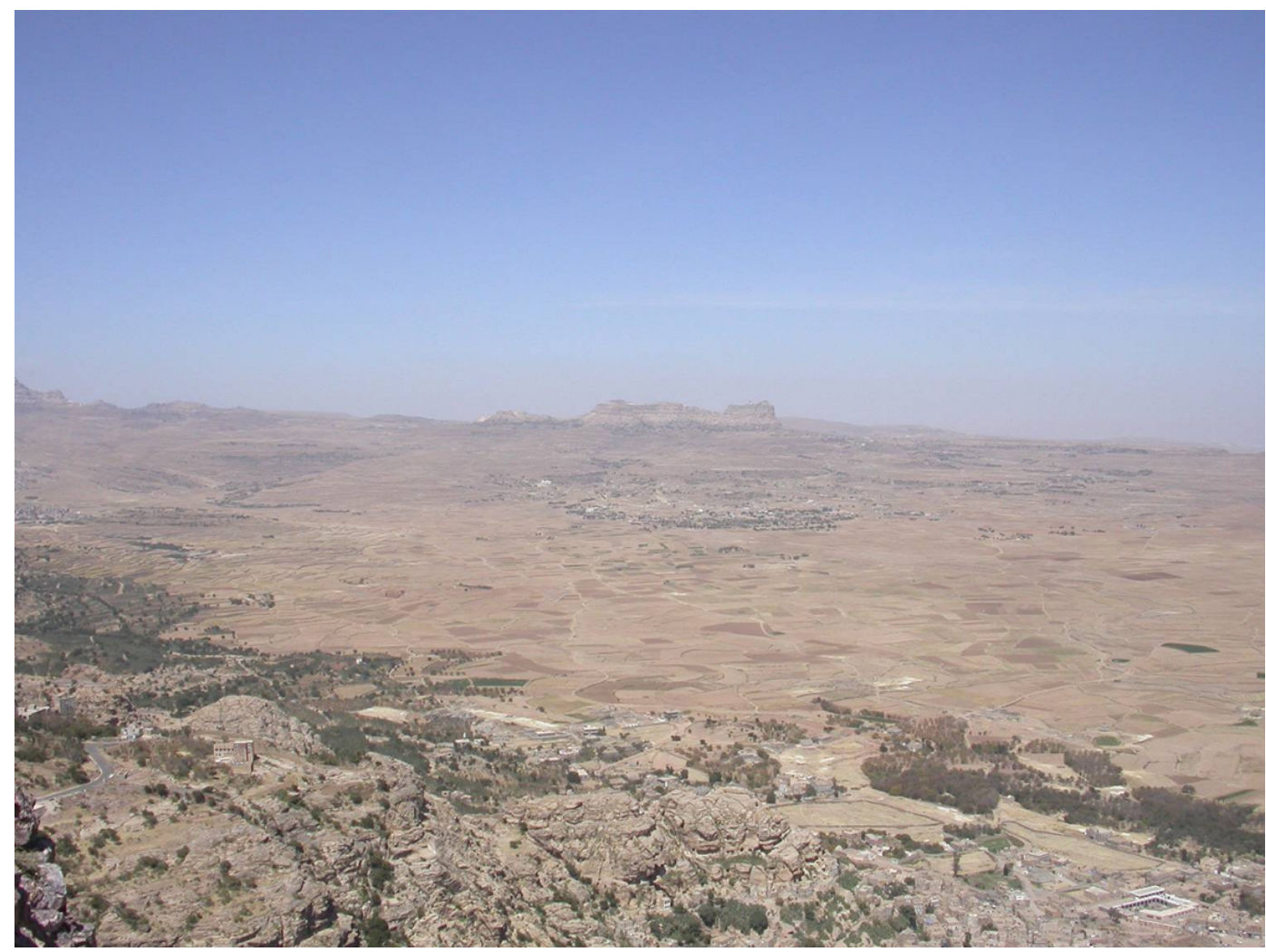

Fig. 3: View to the investigation area northeast of Shibam city, Yemen (photo R. Kringel 11/2006, BGR)

\begin{tabular}{|l|l|l|l|l|}
\hline Sensor type & $\begin{array}{l}\text { Spectral } \\
\text { bands }\end{array}$ & $\begin{array}{l}\text { Spatial res- } \\
\text { olution }[\mathbf{m}]\end{array}$ & Date & Source \\
\hline CORONA & panchromatic & 2.5 & 07.11 .1967 & $\begin{array}{l}\text { USGS } \\
\text { (http://www.usgs.gov) }\end{array}$ \\
\hline QuickBird & color composite & 0.6 & 14.11 .2003 & $\begin{array}{l}\text { Google Earth } \\
\text { (http://earth.google.com) }\end{array}$ \\
\hline SPOT & $\begin{array}{l}\text { RGB, NIR }+ \\
\text { panchromatic }\end{array}$ & $10+2.5$ & 23.04 .2004 & $\begin{array}{l}\text { SPOT IMAGE } \\
\text { (http://www.spot.com) }\end{array}$ \\
\hline
\end{tabular}

Tab. 2: Images used 


\section{Change Detection with GRASS GiS - Comparison of images taken by}

DIFFERENT SENSORS

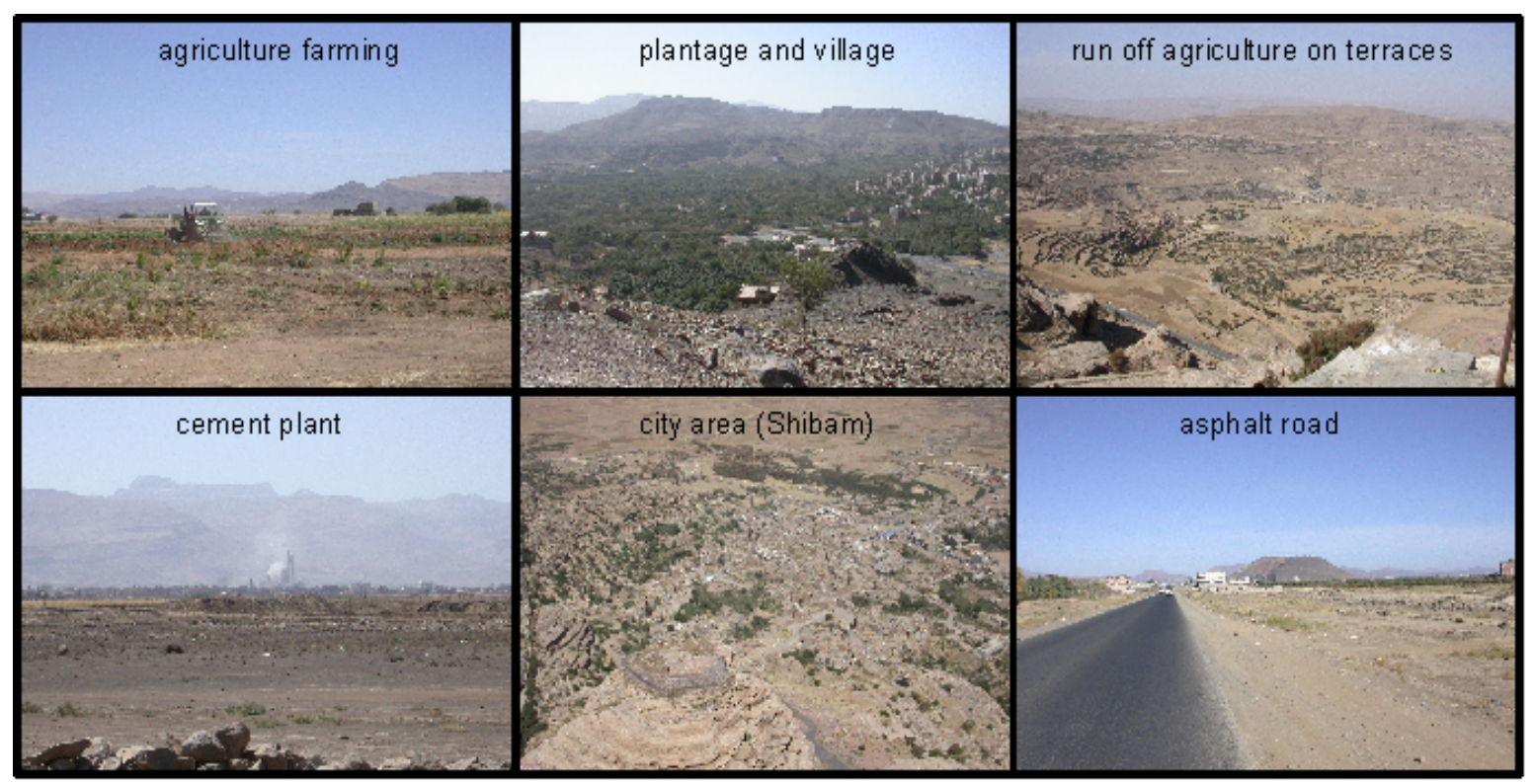

Fig 4: Exemplary land uses in the study area (photos by R. Kringel 11/2006, BGR)

\section{Results}

The first results contain the computed diversity layers derived from the panchromatic images. The diversity/heterogeneity is quantified at date A (Fig. 5) and date B (Fig. 6 -7). Areas with low and high diversity can be delineated and combined with land cover classes. The two entropy layers of QuickBird (Fig. 7) and SPOT (Fig. 6) data show identical patterns in heterogeneity. This is confirmed by the correlation of 0.84 (Tab. 4). In contrast the comparison of diversity between the CORONA image and the modern scenes shows no correlation (Tab. 4).

\begin{tabular}{|l|r|r|r|r|}
\hline layer & minimum & maximum & mean & variance \\
\hline CORONA panchromatic & 0 & 248 & 152.4 & 2348.0 \\
\hline CORONA entropy & 0 & 4.98 & 3.97 & 0.65 \\
\hline CORONA diversity & 1 & 172 & 85.5 & 941.2 \\
\hline QuickBird panchromatic & 0 & 254 & 116.6 & 1338.6 \\
\hline QuickBird entropy & 0 & 5.25 & 4.16 & 0.29 \\
\hline QuickBird diversity & 1 & 224 & 100.2 & 1287.4 \\
\hline SPOT panchromatic & 0 & 230 & 75.3 & 245.9 \\
\hline SPOT entropy & 0 & 4.48 & 3.1 & 0.21 \\
\hline SPOT diversity & 1 & 118 & 34.4 & 166.4 \\
\hline CORONA-QickBird entropy difference & -5.08 & 3.16 & -0.19 & 0.58 \\
\hline CORONA-QuickBird diversity difference & -193 & 130 & -14.7 & 1280.5 \\
\hline CORONA-SPOT entropy difference & -4.06 & 2.81 & 0.87 & 0.61 \\
\hline CORONA-SPOT diversity difference & -84 & 139 & 51.1 & 852.8 \\
\hline
\end{tabular}

Tab. 3: Univariate statistics for input and output layers

The entropy layers mark agriculture terraces, plantations, infrastructure, and settlement areas 


\section{Change Detection with GRASS GiS - Comparison of images taken by DIFFERENT SENSORS}

as highly divers. The visible patterns with high entropy coincide with the border areas of Wadis. This can be explained by intensive human activities and changes in land use. Parts with low entropy comprise areas covered by clouds or shadows, areas on the higher part of the plateaus as well as barren land.
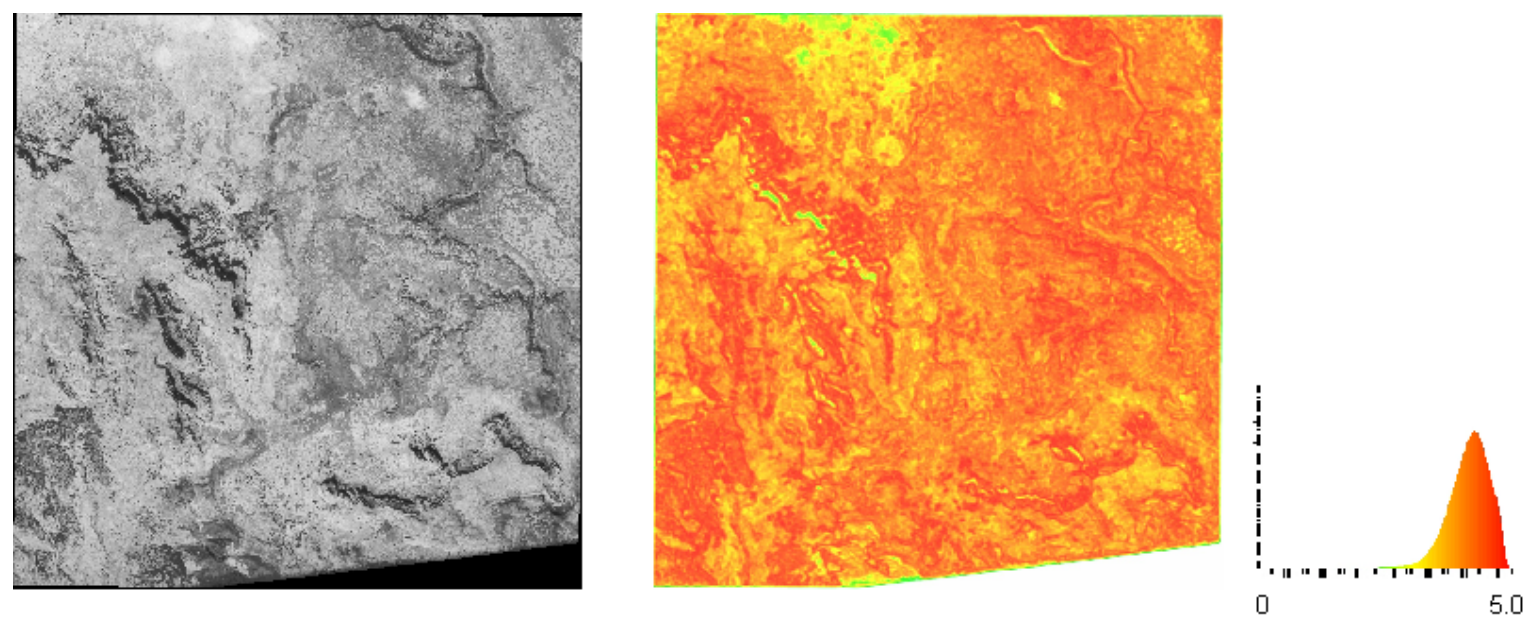

Fig. 5: CORONA image (left), its entropy pattern (middle), and distribution of entropy values (right)
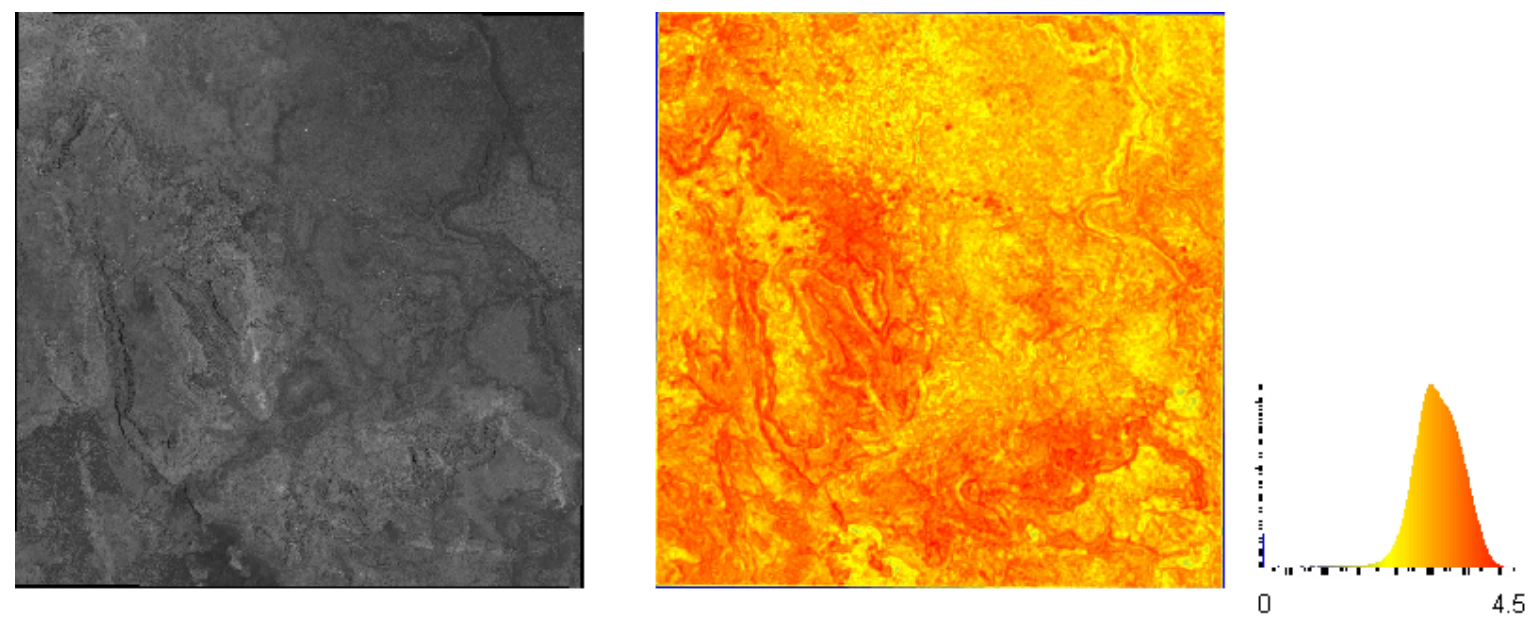

Fig. 6: SPOT panchromatic image (left), its entropy pattern (middle), and distribution of entropy values (right)

\begin{tabular}{|l|l|l|}
\hline entropy layer & QuickBird & SPOT \\
\hline CORONA & 0.43 & 0.34 \\
\hline QuickBird & & 0.84 \\
\hline
\end{tabular}

Tab. 4: Correlation coefficients between the entropy layers

The difference images (difference $=$ CORONA entropy - panchromatic image entropy) illustrate the intensity of change between date A and date B. Areas with shadows and cloud cover have to be neglected, although high differences can occur. For these areas an assessment of change is not possible. The threshold between change and no change is drawn in the middle 

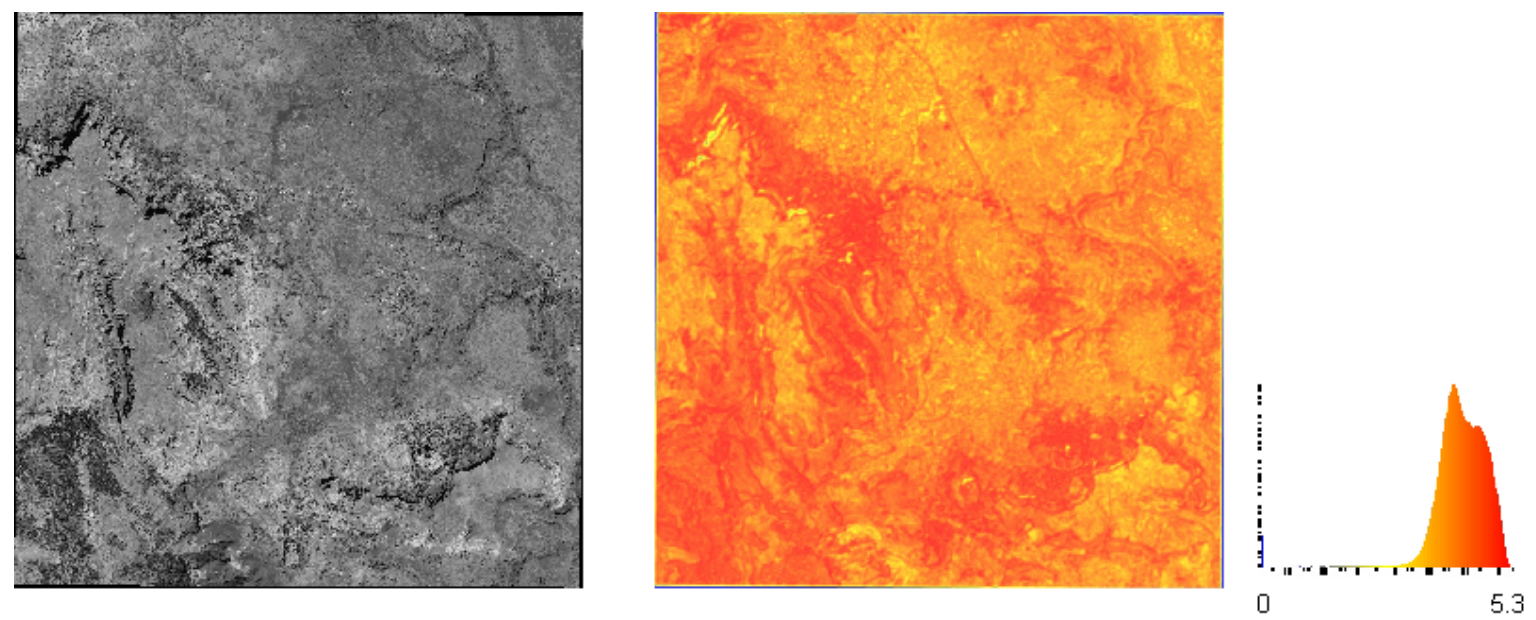

Fig. 7: QuickBird panchromatic image (left), its entropy pattern (middle), and distribution of entropy values (right)

of the distribution of difference values. A negative value stands for change. The smaller the values the stronger is the change (Tab. 3).
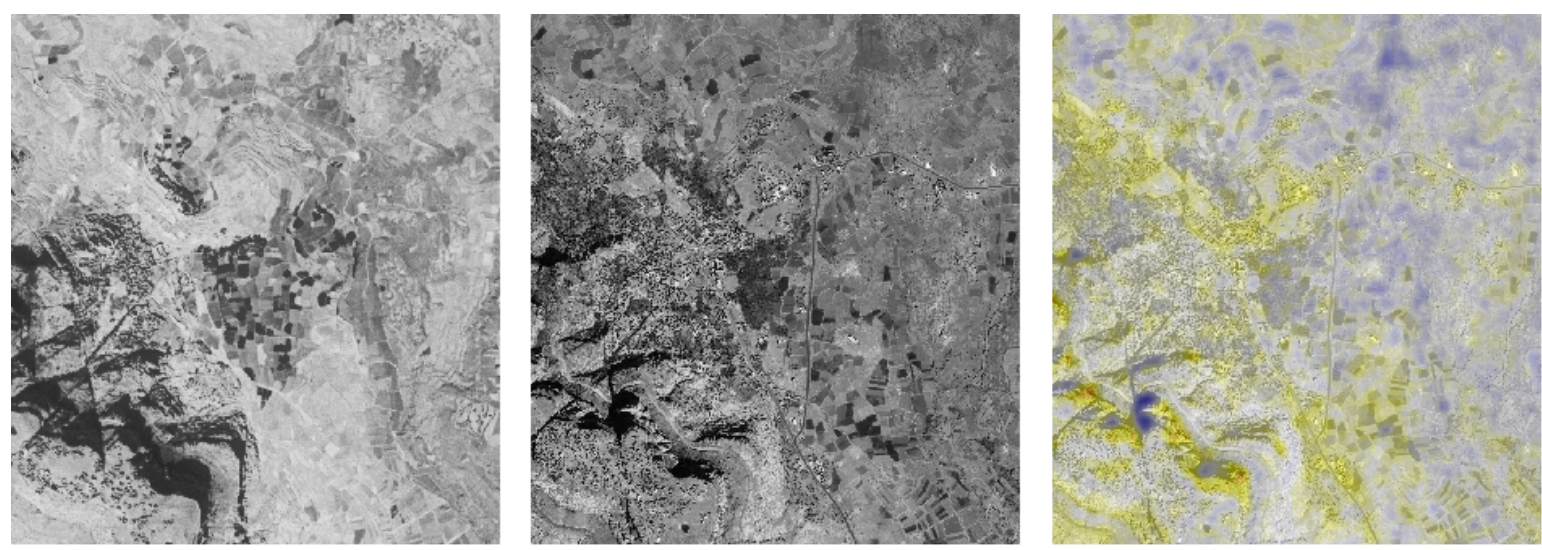

Fig. 8: CORONA, QuickBird image and entropy difference layer of Shibam
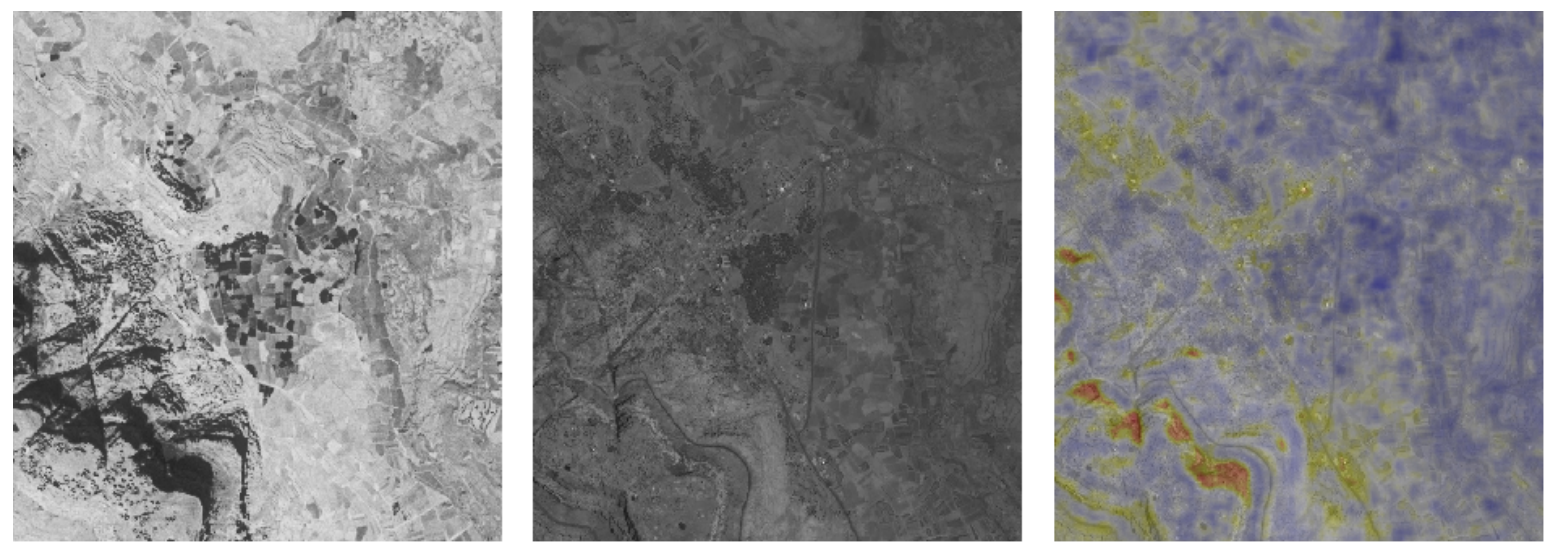

Fig. 9: CORONA, SPOT image and entropy difference layer of Shibam 
The city of Shibam is located in the center of the test site (Fig. 8, 9). In this $2.5 \mathrm{~km}^{2}$ clipping area the readability of the entropy difference pattern is depicted (Fig. 8, 9). Negative difference values have an orange-yellow coloring and are plotted transparently on the panchromatic image. Areas with very strong differences are marked by shadows (visible along the geological fault zone, Fig 8 and 9 left). These areas were not considered in the final generalization pattern. The remaining pattern clearly reflects the distribution of building areas and infrastructure at the edge of the town as well as changes in land use. Therefore both resulting entropy difference layers show an identical pattern.

Shadows and clouds were eliminated for the difference patterns by masking and the remaining patterns were generalized. As result several categories can be distinguished (Fig. 10):

- extension of settlements (1)

- urban sprawl as result of construction of new roads (2)

- plant settlement (3)

- extension of plantation (4)

The areas shown in Fig. 10 mark the areas with changes due to human activities. Even in this rural area changes in infrastructure - mainly construction of new roads - and urban sprawl are clearly visible. During the last four decades the changes have reached a considerable dimension so that the size of the city now is twice as large.

The use of CORONA images for Change Detection (simple image differencing method) increases the evaluated period by one decade. The entropy and diversity difference images show plausible and interpretable change pattern. The comparison of CORONA images of the Sixties with images taken by modern sensors turned out to be a promising complement approach to visualize and quantify major changes in land use.

\section{References}

1. Altmann, R.; Haase, G. (1987): Zur Kennzeichnung von Merkmalsvariabilität, Kontrast und Arealheterogenität als Eigenschaften der Landschaftsstruktur". Strukturen und Prozesse in der Geographie: Beiträge zur quantitativ arbeitenden Geographie, Band 19, 145-154, Haack: Gotha.

2. Bjorke, J. (1996): Framework for Entropy-based Map Evaluation. Cartography and Geographic Information Systems, 23, 2, 78-95.

3. GRASS (2008): Geographic Resources Analysis Support System, GRASS GIS 6.3.0 http://grass.osgeo.org

4. Grosse, G.; Schirrmeister, L.; Kunitsky, V. V.; Hubberten, H.-W. (2005): The Use of CORONA Images in Remote Sensing of Periglacial Geomorphology: An Illustration from the NE Siberian Coast. Permafrost and Periglac. Process. 16: 163-172.

5. Goossens, R.; De Man J.; De Dapper M. (2001): Research on the possibilities of CORONA-satellite-data to replace conventional aerial photographs in geo-archaeological 


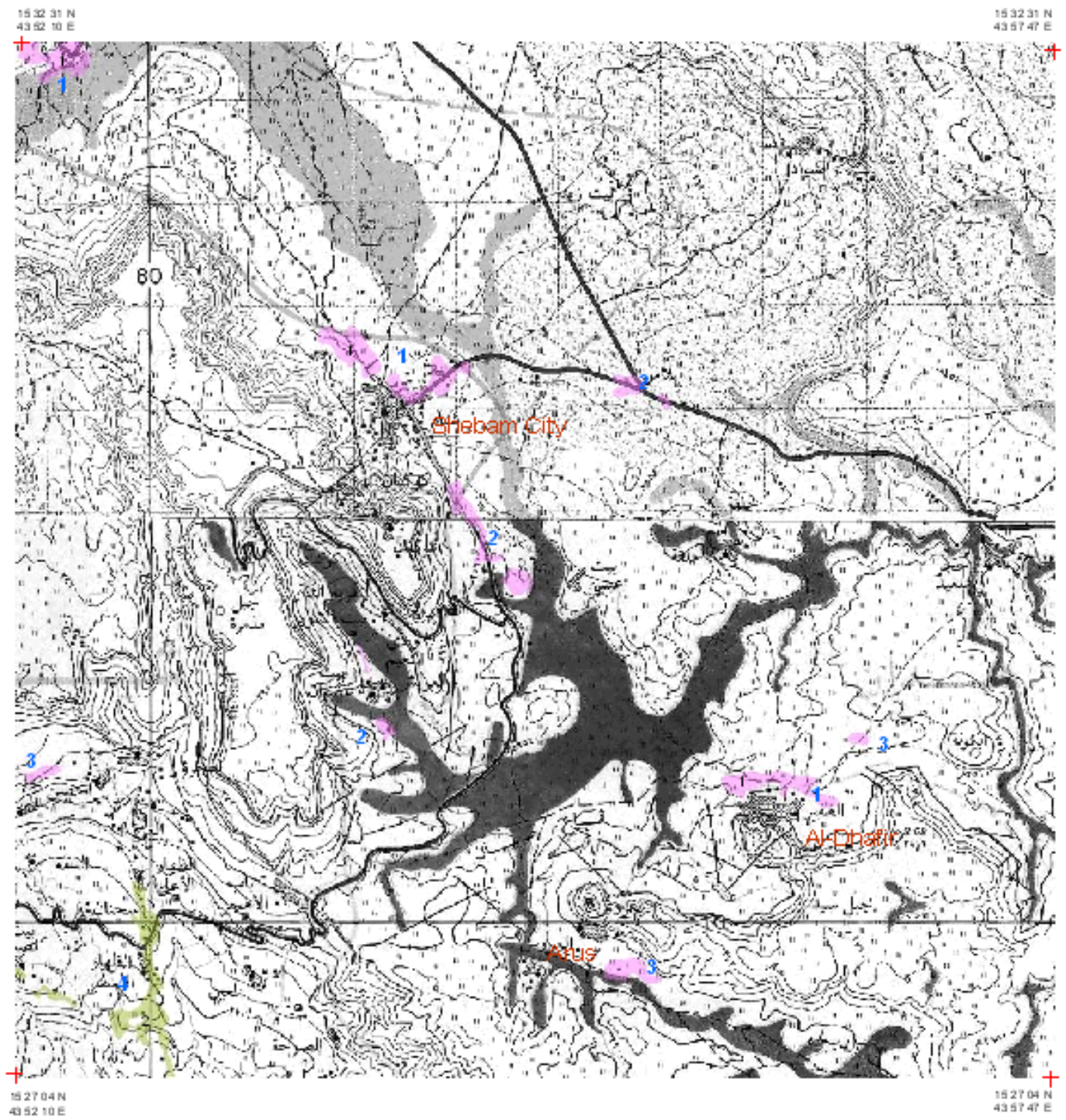

Fig. 10: Changes in land use marked on topographic map from the eighties.

studies, practised on Sai (Sudan). In A Decade of Trans-European Remote Sensing Cooperation, Buchroithner MF (ed.). Balkema Publishers: Lisse/Netherlands; 257-262.

6. Lorenz, H. (2004): Integration of Corona and Landsat Thematic Mapper data for bedrock geological studies in the high Arctic. International Journal of Remote Sensing, Volume 25, Number 22: 5143-5162.

7. Lunetta, R. S.; Elvidge, Ch. D. (eds.) (1999): Remote sensing change detection: environmental monitoring methods and applications, Taylor \& Francis, London.

8. McGarigal, K.; Marks B. J. (1995): FRAGSTATS: spatial pattern analysis program for quantifying landscape structure. USDA For. Serv. Gen. Tech. Rep. PNW-351.

9. Owe, M. (ed.) (2007): Remote sensing for environmental monitoring and change detection: a compilation of papers presented at the IAHS Symposium on Remote Sensing 
for Environmental Monitoring and Change Detection, in Perugia, as part of the 24th IUGG General Assembly, 2007, IAHS publication, 316.

10. Palm, G. (1985): Information und Entropie. In: Natur und Wissenschaft. Konkursbuch 14, Zeitschrift für Vernuftskritik, 95-110. Tübingen: Konkursbuchverlag.

11. Paulov, J. (1991): Entropie in der Humangeographie - Einleitende konzeptionelle Übersicht. Petermanns Geographische Mitteilungen 2/1991, 89 - 97, Gotha: Haack.

12. Peinado, L. O. (2001): Comparison of Change Detection Methods for the Extraction of Land Cover Parameters. Herbert Utz.

13. Schmidt, M.; Goossens, R.; Menz, G.; Altmaier, A.; Devriendt, D. (2001): The use of CORONA satellite images for generating a high resolution digital elevation model. IEEE vol. 7: $3123-3125$.

14. Théau, J. (2006): Detection of Changes Using Remote Sensing: an Overview of Principles and Applications. Geo-Spatial and Range Sciences Conference, online ${ }^{1}$.

15. Yang, X. M. (1999): Change Detection Based on Remote Sensing Information Model and its Application on Coastal Line of Yellow River Delta. GISdevelopment-Proceedings, online $^{2}$.

${ }^{1}$ http://giscenter.isu.edu/gisday/grsc_archives/chdetection.pdf

${ }^{2}$ http://www.gisdevelopment.net/aars/acrs/1999/ps5/ps5043.asp 
